http://jmscr.igmpublication.org/home/ ISSN (e)-2347-176x ISSN (p) 2455-0450 crossref DOI: https://dx.doi.org/10.18535/jmscr/v7i11.65

\title{
Chronic Meningitis and Hydrocephalus after Traumatic Brain Injury: A Case Report
}

Authors

\section{Vishal Bhatt ${ }^{1}$, Santoshkumar Thakur ${ }^{2}$}

\begin{abstract}
Chronic Meningitis accounts for fewer cases of meningitis. It is very difficult to find the culprit organism and treat the same. Complications like hyponatremia, hydrocephalus, neurological impairement should always be suspected early in patients with chronic meningitis and should be treated with multidisciplinary team approach. We encountered a case of traumatic brain injury who eventually developed meningitis, hydrocephalus and was treated for same multiple times and was discharged home with some neurological impairment.
\end{abstract}

\section{Introduction}

Chronic meningitis, accounts for $10 \%$ cases of meningitis and is defined as meningeal inflammation that persits for more than 4 weeks. Causes can be infectious, autoimmune, malignant diseases or chemical. Despite the availability of increasingly effective antibiotics and intensive neurological care, the overall mortality remains high, with $17-34 \%$ of the survivors having unfavorable outcomes ${ }^{[1]}$. Neurological complications associated with bacterial meningitis are major contributing factors to this high disability and mortality among survivors. We are presenting a case of young male who developed chronic meningitis and its complications after traumatic brain injury.

\section{Case Presentation}

A 22 year male presented to emergency room (ER) with alleged history of road traffic accident (RTA). On admission patient's airway was patent, breathing was normal with respiratory rate of 18 per minute and no adventitious sounds were heard. Circulation revealed heart rate of 90 beats per minute with blood pressure of 136/80 mmh. GCS was $11 / 15$ and pupils bilaterally equal and reacting to light. Fracture of the left frontal was palpable. No other injuries noted. CT scan of brain was done which showed left frontal bone fracture with frontal sub dural hematoma (SDH) with cerebral edema with pneumocephalus.

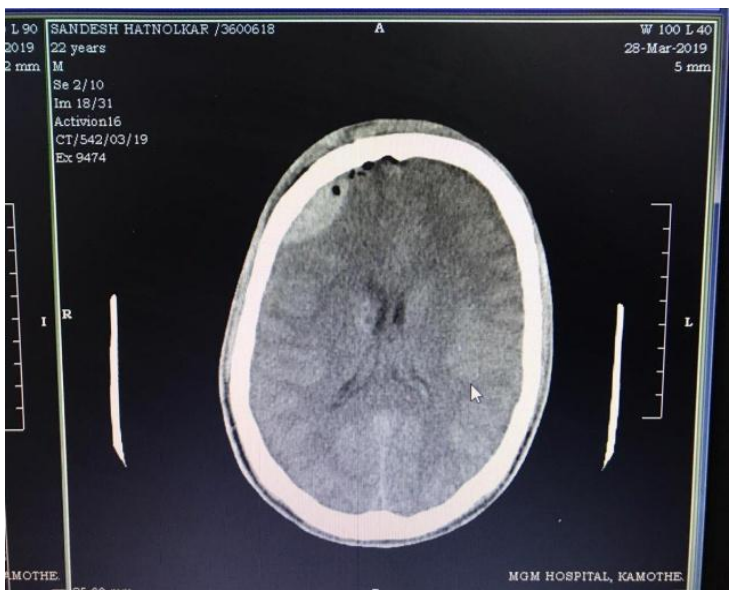

Fig. 1 Cerebral edema with left SDH with pneumocephalus 


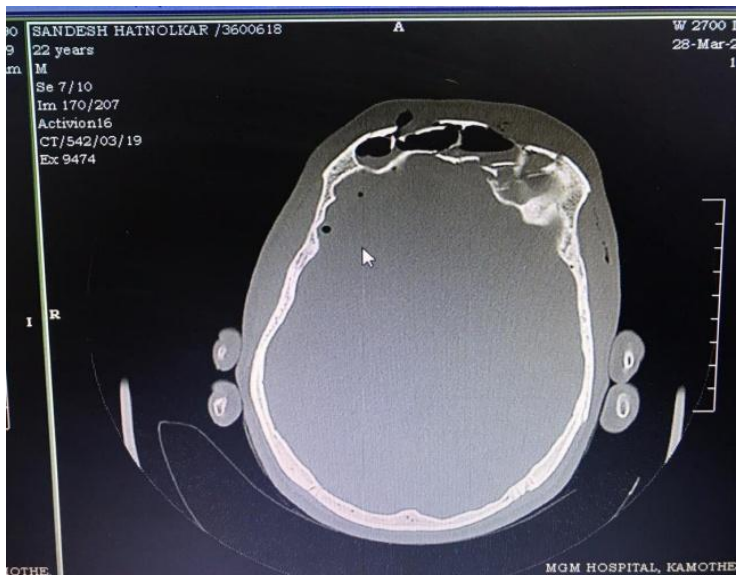

Fig. 2 Left Frontal bone fracture with pneumocephalus

Patient was started on oxygen, $3^{\text {rd }}$ generation cephalosporin with antiepileptics and mannitol and was shifted to ICU for further management. 3 days later patient developed fever spikes and neck stiffness. CSF examination was done which showed 4000 cells with neutrophilic predominance. CSF glucose and protein were 18 and 137 respectively and patient was diagnosed as bacterial meningitis. CSF culture revealed gram negative organism. CSF gram stain was negative. CT scan was repeated which revealed no new findings.

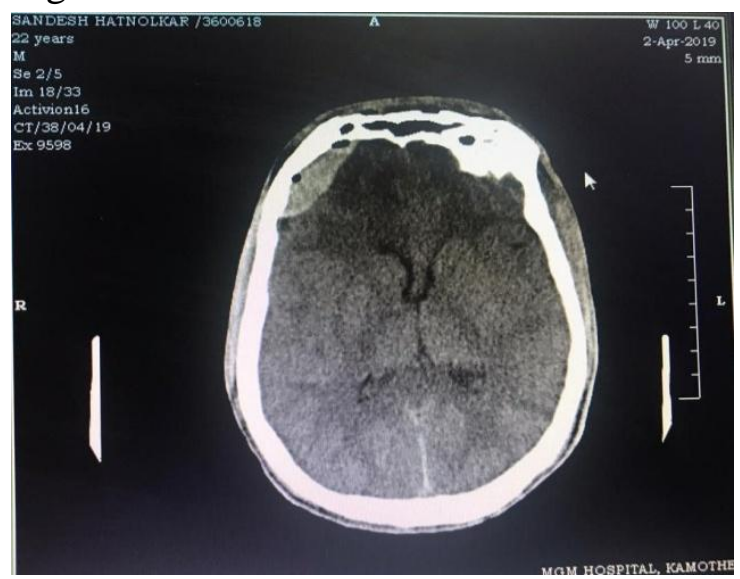

Fig.3 Repeat scan after 72 hours- no new findings

Patient's serology status was done which was negative. After 2 weeks of treatment patient improved completely and was discharged. After 3 weeks patient presented to ER with fever \& altered sensorium with GCS of 8. Patient was mechanically ventilated in view of threatened airway. Repeat CT revealed dilated ventricles with calcified scar over frontal region.

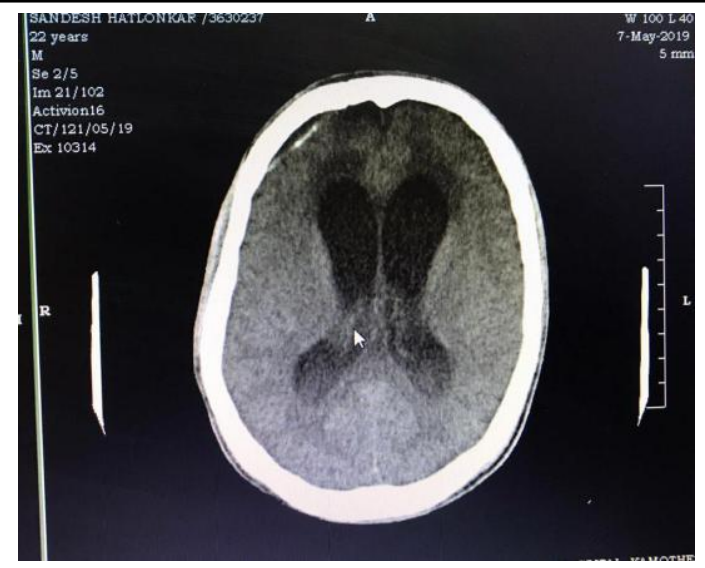

Fig. 4 Dilated lateral ventricles with calcified scar over left frontal region

CSF revealed neutrophilic predominance suggestive of bacterial meningitis and was started on higher antibiotics. CSF Gram stain was negative Patient's GCS improved and was extubated in 72 hours. 4 days letter patient developed polyuria and polydypsia and serum sodium was $128 \mathrm{mmol} / \mathrm{l}$. A diagnosis of cerebral salt wasting syndrome (CSWS) was suspected. Urine sodium and urine osmolality were normal. TSH was $2.5 \mathrm{mIU} / \mathrm{ml}$, FT3 was $0.4 \mathrm{ng} / \mathrm{dl}$ and FT4 was $1.2 \mathrm{ng} / \mathrm{dl}$. After normal thyroid and urine report a diagnosis of psychogenic polydypsia was made. Patient improved and discharged after 4 weeks. 3 weeks later patient presented to ER with altered mental status and fever and was found to have severe hydrocephalus in CT.

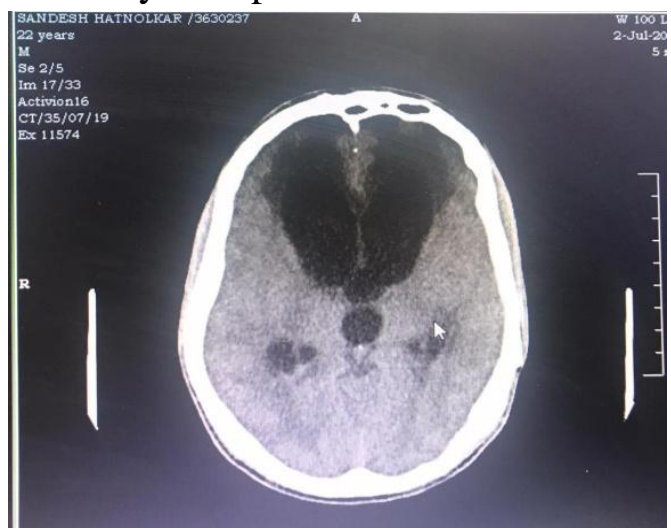

Fig.5 Significant Hydrocephalus on CT scan External ventricular drain (EVD) was inserted and antibiotics continued. Patient improved in 10 days. Patient developed ataxia during the course of treatment and was discharged with complete hemodynamic stability and GCS of $15 / 15$ with ataxia as neurological impairment. 


\section{Discussion}

Chronic meningitis causes numerous complications which increases the mortality as well as morbidity of the patient.

Table 1 Complications of Chronic Meningitis ${ }^{[2]}$

\begin{tabular}{|l|c|}
\hline Complications & Percentage seen \\
\hline Cerebrovascular complications & $14-37$ \\
\hline Vestibulocochlear neuropathy & $22-54$ \\
\hline Altered Mental status & 80 \\
\hline Hydrocephalus & $3-21$ \\
\hline Seizures & $15-30$ \\
\hline Subdural empyma & 5 \\
\hline Ventriculitis & 54 \\
\hline Brain abscess \& focal cerebritis & $9-43$ \\
\hline $\begin{array}{l}\text { Cognitive \& Neuropsychiatric } \\
\text { impairments }\end{array}$ & 32 \\
\hline $\begin{array}{l}\text { Hypothalamic \& Endocrine } \\
\text { insuffiency }\end{array}$ & Rare \\
\hline Myelopathy \& Radiculopathy & Rare \\
\hline
\end{tabular}

Hydrocephalus occurs in $3-21 \%$ of patients ${ }^{[3,4,5]}$. This condition is associated with higher mortality and poorer neurological outcomes.38,39 Because the infection affects primarily the meninges, communicating hydrocephalus due to blockade of CSF absorption by leptomeningeal inflammation is more common. Obstructive hydrocephalus due to aqueduct obstruction is less common and can result from infected debris or complicated intraventricular pus as found in this case. Mild to moderate hydrocephalus can be conservatively managed with close monitoring; severe hydrocephalus causing increased intracranial pressure must be treated with neurosurgical intervention.

\section{Conclusion}

Although few patients have neurological impairment in chronic meningitis and are discharged with permanent disability, effective management and multidisciplinary team approach helps in reducing the morbidity as well as mortality in these patients.

\section{References}

1. Satish V Khadilkar1, Nilesh Nadkarni2 Approach to Chronic Lymphocytic Meningitis Journal of the Association of
Physicians of India Vol. 63 September 2015.

2. Bacterial meningitis and neurological complications in adults Parunyou Julayanont MD, Doungporn Ruthirago MD, John C. DeToledo MD Bacterial meningitis and neurological complications in adults. The Southwest Respiratory and Critical Care Chronicles 2016;4(14)

3. Kasanmoentalib ES, Brouwer MC, van der Ende A, van de Beek D. Hydrocephalus in adults with community acquired bacterial meningitis. Neurology 2010; 75(10):91823.

4. Bodilsen J, Schønheyder HC, Nielsen H. Hydrocephalus is a rare outcome in community-acquired bacterial meningitis in adults: a retrospective analysis. BMC Infect Dis 2013; 13:321.

5. Wang K-W, Chang W-N, Chang H-W, Wang $\mathrm{H}-\mathrm{C}$, Lu C-H. Clinical relevance of hydrocephalus in bacterial meningitis in adults. Surg Neurol 2005; 64(1):61-5; discussion 66. 